\title{
Estado e Federação: uma discussão para o Brasil
}

\author{
Demian Castro ${ }^{1}$ \\ Fernando Motta Correia ${ }^{2}$
}

Resumo: Este artigo faz um balanço do federalismo fiscal brasileiro desde a República Velha até os primeiros anos do século XXI. Procura-se focalizar três grandes etapas, a primeira, até o início dos anos 1960, marcada pela trajetória de constituição da indústria pesada e do mercado interno do País. A segunda etapa, sob uma dinâmica industrial associada ao regime autoritário. A terceira etapa, inicia-se com o período de redemocratização, contemplando um processo de transição e consolidação democrática. Para além da questão complexa da periodização utilizada, o artigo mostra a predominância de relações federativas não cooperativas e, via de regra, com pouquíssimo grau de coordenação. Concomitantemente, aponta-se a vigência de uma tradição estadualista, interrompida durante boa parte do regime autoritário e, mais recentemente, debilitada por um processo de descentralização fiscal. O artigo conclui questionando a capacidade do Estado e dos entes federados de atender às demandas sociais num ambiente perpassado pela existência de novos atores sociais.

Palavras-chave: Estado; federalismo; descentralização fiscal.

\section{State and federalism: overviewing the Brazilian case}

Abstract: This article analyzes the Brazilian fiscal federalism from the Old Republic to the first years of the $21^{\text {st }}$ century. It stresses three time periods. The first, until the beginning of the sixties, is marked by the constitution of a base industry and of a mass internal market. The second runs under an industrial dynamics associated with the authoritarian regime. The third begins with the

1 Professor do Departamento de Economia da UFPR. E-mail: demian@ufpr.br

2 Aluno do Programa de Pós - Graduação em Desenvolvimento Econômico da UFPR. E-mail: fmottabr@yahoo.com.br 
transition towards democracy consolidation. Besides the complex subject of the used division of stages, the article shows the predominance of non cooperatives federative relations between the Brazilian states, road-of-rule, with very little coordination degree. Meanwhile, the validity of a tradition local of the states interrupted during good part of the authoritarian regime and, more recently, weakened by a process of fiscal decentralization. The article concludes questioning the capacity of the State and of the federated beings of assisting to the social demands in an atmosphere through the new social actors existence.

Key words: State; federalism; fiscal decentralization.

JEL: $\mathrm{H}_{700}$; H770; H790

\section{INTRODUÇão}

Ao longo do processo histórico brasileiro, as discussões sobre economia e política não podem estar desassociadas à natureza do Estado, sendo este dotado da capacidade de servir e articular a vida social. Todavia, profundas mudanças políticas e econômicas colocam, muitas vezes, em crise o papel do Estado.

No Brasil, as características e peculiaridades do federalismo fiscal podem auxiliar nos diferentes momentos e configurações que o Estado brasileiro assumiu ao longo da história.

O estudo sobre o federalismo refere-se à análise da distribuição de poder entre esferas de governo que compõem um Estado nacional. Em alguma medida, a dimensão federal do Estado e o exercício de governar, numa nação, podem ser entendidos, a título de aproximação, como uma divisão do trabalho específica que distribui ao longo do tempo, entre as unidades federadas, direitos e deveres expressos, de modo geral, na produção de bens públicos e semipúblicos. Contudo, muitas vezes essa divisão do trabalho é mais uma constatação ex post do que um arranjo explícito entre as unidades federativas.

Por outro lado, esse aspecto concreto também é traduzido pela existência de anéis de poder regional que "originalmente" se estabeleceram na nação e que, em última instância, são os executores no processo de construção das estruturas governamentais subnacionais, responsáveis também pela construção de arranjos federativos frouxos. O Estado, enquanto categoria produzida no processo de constituição do capitalismo no Brasil, carrega inúmeras marcas desses anéis de poder presentes desde o período do Império, no século XIX. Desde essa época, os arranjos federativos traduzem concretamente as dificuldades de constituição do Estado no âmbito de uma formação capitalista tardia e periférica. 
É possível afirmar que, na falta de um mercado interno integrador, as relações federativas eram pouco desenvolvidas e que, nesse contexto, a Federação era muito mais a expressão do atraso do que a da modernização decorrente do avanço da industrialização. A outra face desse mesmo problema diz respeito ao processo de integração comercial impulsionado pela industrialização concentrada em São Paulo desde o início do século XX e que ganha novo alento a partir da crise dos complexos agroexportadores nos anos 1930.

Nesse sentido, as relações federativas presentes desde a independência do país antecedem temporalmente o processo de constituição da indústria ou das forças produtivas especificamente capitalistas, em cujo seio é gerado o Estado capitalista. Entre a independência nacional, em 1822, e a implantação da indústria pesada em fins dos anos 1950, o Estado brasileiro foi com muita freqüência caudatário dos anéis de poder regional, enfrentando resistências em sua tarefa de centralização e unificação do poder de cunho capitalista. No entanto, não convém negar o papel do governo central na resolução das crises periódicas do principal complexo agroexportador capitalista do país até os anos 1930 e, depois, durante o Estado Novo para romper com as autonomias regionais de base agrário-exportadora.

O objetivo deste artigo é discutir as relações federativas no País sem perder de vista a questão da formação do Estado capitalista no País até o início dos anos 1960 e seus desdobramentos na fase pós autoritarismo. Estudando esse fenômeno, Draibe (1985) caracteriza um Estado de transição ao capitalismo que se encerra após o Plano de Metas. Para a autora, nesse período a centralização federativa do Estado foi sendo constituída num processo contraditório, não linear, que, entre outras coisas, traduz as dificuldades de integrar a nação sem a existência de forças produtivas especificamente capitalistas.

Dentro dessa linha de análise, parece interessante estabelecer no estudo do federalismo um grande divisor de águas no limiar das décadas de 1950 e 1960, buscando caracterizar também uma grande etapa de formação do federalismo vinculado às possibilidades de constituição da indústria pesada e do mercado interno nacional. Segundo Draibe (1985:79): "A ampliação das bases fiscais do Estado foi relativamente lenta, no período em pauta, e os recursos de que dispunha a União tiveram crescimento inferior ao da renda nacional."

Na verdade, para além da questão dos movimentos de centralização e descentralização, esse divisor de períodos pressupõe que o desenvolvimento das relações federativas passa pelas condições materiais capazes de gerar circuitos nacionais para o capital e, também, pelo caráter desigual desse processo. Nesse sentido, o federalismo muda de natureza 
com a integração nacional propiciada pela instalação da indústria pesada. Essa demarcação temporal, que não nega a complexidade dos fenômenos de distribuição do poder pré-anos 1960, também rebate sobre a natureza da discussão sobre os graus de autonomia ou subordinação dos governos subnacionais ao governo central. Varsano (1996:24) afirma que os maiores desafios do federalismo brasileiro, independentemente dos ciclos de maior ou menor centralização tributária, têm sido atender ao ideal de, por um lado, assegurar autonomia política e financeira aos Estados e, por outro, garantir a coordenação e sistematização nacional dos instrumentos fiscais. Portanto, se a existência de bases materiais e mecanismos fiscais adequados é condição necessária para gerar fundos públicos capazes de articular a Federação, ela não é suficiente para garantir a melhor escolha e distribuição de bens públicos e semipúblicos entre as suas esferas.

Além desta introdução, o artigo contempla mais quatro seções, onde procura-se focalizar três grandes etapas. A segunda seção apresenta a primeira etapa, da República Velha até o início dos anos 1960, marcada pela trajetória de constituição da indústria pesada e do mercado interno do País. A seção seguinte apresenta a segunda etapa, sob uma dinâmica industrial associada ao regime autoritário. A quarta seção, com a terceira etapa, inicia-se com o período de redemocratização, contemplando um processo de transição e consolidação democrática. Por fim, a seção cinco apresenta as principais conclusões do estudo.

\section{Da República Velha ao golpe de 1964}

O primeiro período refere-se à República Velha e ao pacto oligárquico que, a posteriori, surgiu como categoria síntese para caracterizar o relacionamento nacional entre os vários anéis (ou blocos) de poder e respectivos complexos exportadores sob o domínio do cafeeiro. Por esse pacto, os vários grupos de poder regional, sob a condição de continuar a manter, nas respectivas jurisdições, os mecanismos de superexploração e violência sobre a força de trabalho e de apropriação unilateral dos meios de produção e dos aparelhos públicos subnacionais, subscreviam a existência de um poder central. A era dos chamados "arquipélagos regionais", num vastíssimo território como o brasileiro, permitiu que esse padrão de relacionamento tácito sobrevivesse, apesar das suas contradições, pois o pacto não assegurava a equalização de ganhos diante da superioridade econômica do complexo cafeeiro. Este, em geral, ditava os rumos da política econômica.

Segundo Varsano (1996), a República brasileira herdou do Império quase toda a estrutura tributária que vigorou até os anos 1930. A Constituição 
de 1891, apontando para uma república federativa, concedeu aos Estados um novo status político pelo qual poderiam atuar em qualquer área do seu interesse, usando recursos originados dos impostos de exportação, operações de dívida pública e empréstimos externos. Definindo competências tributárias, a União ficou com o imposto de importação, taxas diversas e direitos sobre a entrada e saída de navios. Nesse cenário, os Estados com complexos agroexportadores mais dinâmicos, em especial o cafeeiro, saíam-se beneficiados. Para uma parcela importante de Estados mais frágeis, não restou outra alternativa senão usar e abusar da tributação sobre operações interestaduais de compra e venda de mercadorias, criando entraves para o desenvolvimento do mercado interno. De resto, como havia autonomia para legislar sobre tributos, os Estados puderam introduzir inúmeros outros impostos sobre operações diversas de âmbito estadual, porém, sem resultados consistentes em termos de arrecadação. Desde cedo, portanto, um conjunto relevante de Estados com menor dinamismo econômico se tornou dependente da capacidade política de obter parcelas de recursos do orçamento da União ${ }^{3}$. Note-se que esse formato tributário foi bastante eficaz para sustentar os interesses cafeeiros e, ao mesmo tempo, atender aos requisitos do crescimento industrial produzido pela dinâmica do complexo cafeeiro (Lopreato 2002:15 et seq.).

Esse pacto oligárquico e o federalismo fiscal correspondente ganhavam validade na ausência de mecanismos centralizadores do Estado. A crise dos complexos, em especial do cafeeiro, e a Revolução de 1930 abriram um novo período marcado pelo avanço na construção de aparelhos centralizadores do Estado no seio da dinâmica de industrialização restringida. As novas possibilidades de crescimento, em virtude da expansão, principalmente, da indústria de bens de consumo salário, ajudaram a abrir as fronteiras internas que diferenciavam as várias economias para fora e separavam os Estados brasileiros, impedindo sua integração comercial.

\subsection{Estado e instrumentos regulatórios: uma análise do período 1930-1945}

\footnotetext{
3 Segundo Lopreato (2002:18), “As receitas dos impostos interestaduais constituíam norma e representavam parcela importante da receita tributária de que os governos estaduais se valiam para atender aos gastos. Entretanto, sem dispor de autonomia financeira para suprir os requerimentos de acumulação, eles reproduziam suas formas internas de dominação pela articulação específica que mantinham com a União, seja por meio de transferências fiscais, seja simplesmente por manejos de inserção no próprio orçamento federal, política de emprego ou política de clientela junto aos órgãos federais.”
} 
Entre 1930 e 1945, interregno marcado quase integralmente pelo autoritarismo do Estado Novo, avançou a construção dos aparelhos centralizadores do Estado e, portanto, a capacidade de intervenção econômica e social da União em detrimento dos Estados. Embora tenha havido mudanças importantes em termos de principais impostos arrecadados (no âmbito da União, o imposto de importação cedeu lugar, primeiro, ao imposto de consumo e, depois, ao imposto de renda; nos Estados, por sua vez, o imposto de exportação deu lugar ao impostos sobre valores e consignações - IVC, criado em 1934), refletindo uma dinâmica econômica mais endógena, não houve grandes mudanças na distribuição intergovernamental e regional da receita tributária total. Varsano (1996) e Lopreato (2002) coincidem em afirmar que o formato institucional do federalismo fiscal manteve inalteradas as características pré-1930: bastante autonomia para as unidades mais dinâmicas e elevada dependência das unidades economicamente mais frágeis.

\subsection{Formação do setor produtivo estatal: o período 1945-1960}

Com o fim do Estado Novo em 1946, o país iniciava um ciclo democrático até o golpe militar de 1964, período de quase vinte anos em que houve muitas mudanças na base econômica, no Estado e na Federação. No âmbito dos Estados, constatou-se certa recuperação do poder perdido, mesmo porque a reabertura do Congresso Nacional significava recuperar a expressão política das elites regionais ${ }^{4}$. Embora a nova Constituição não tenha alterado profundamente os traços mais característicos do sistema tributário de 1934 e 1937, houve um esforço bastante claro e relativamente contínuo no sentido de coordenar e sistematizar os instrumentos fiscais e as competências tributárias. No entanto, o espaço para a introdução de alterações no campo tributário pelos Estados e, a partir de 1946, pelos municípios, continuou sendo amplo e, mais grave, gerador de enorme ineficácia do esforço arrecadador conjunto das três esferas de governo. Nesse período, observou-se alguma perda, de participação da União na arrecadação da receita total em contraposição a um ligeiro ganho de participação dos governos estaduais. Isso pode ser observado com a introdução de um sistema de compartilhamento de tributos na Constituição de 1947, o que conduziu a uma maior descentralização fiscal.

4 Segundo Rodriguez (1995:441): "O intervalo democrático de 1946 até 1964 foi um período de ampliação da participação e competição eleitoral, fortalecimento jurídico e político dos municípios e reconquista das autonomias estaduais. Ainda assim, já não foi possível recompor o estadualismo nos moldes do período 1907-1930, conhecido na literatura como "Política dos governadores", pois as bases estruturais e políticas do País tinham sido alteradas no período anterior." 
Durante os "cinqüenta anos em cinco" de Juscelino Kubitschek, em que foi completada uma primeira etapa de instalação da indústria pesada e, portanto, das bases materiais necessárias para completar a formação, ou encerrar a transição, do Estado capitalista, o pacto do poder estabeleceu um relacionamento federativo que ilustrava os obstáculos que o presidente não queria enfrentar caso desejasse ser bem-sucedido no Plano de Metas. Mais uma vez, a instalação dos setores modernos não deveria ser objeto de disputas regionais, sob o risco de inviabilizar o projeto industrializante; grosso modo, a implantação da indústria pesada não deveria passar por barganhas dos anéis ou blocos regionais de poder. É bastante conhecido o fato de que, para efeitos do Plano, foi montado o que, depois, foi conhecido como um Estado paralelo bem representado pelos chamados grupos executivos e pelo Conselho de Desenvolvimento Industrial. Esse arranjo de poder reservou os recursos orçamentários para acomodar os interesses regionais e, simultaneamente, financiava déficits fiscais crescentes por meio da emissão monetária, cujos efeitos inflacionários eram precariamente controlados pela expansão acelerada do produto e a entrada de capital estrangeiro.

No entanto, a mudança da base material demonstrava seu anacronismo em relação ao arsenal de impostos e taxas disponíveis, isto é, a consolidação de uma economia industrial não pôde traduzir-se em elevação das receitas públicas porque estas ainda focavam um cenário econômico que estava sendo superado. Durante e após o Plano de Metas, as limitações do arranjo fiscal brasileiro foram se tornando cada vez mais evidentes, e as dificuldades desse padrão de financiamento público, nos primeiros anos da década de 1960, mostravam seu esgotamento histórico. Apesar de ter conquistado bases materiais capitalistas, o Estado brasileiro, durante o esgotamento do ciclo de investimentos, foi dardejado por inúmeras demandas e mostrou-se incapaz de atendê-las sem mudar o arcabouço institucional do sistema tributário e do seu padrão de financiamento, o que, obviamente, envolvia o redesenho do federalismo fiscal. Até esse momento, o federalismo brasileiro pouco ou nada tinha feito para superar os graves problemas regionais do País, apesar dos inéditos e insuficientes mecanismos de redistribuição da renda pública de $1946^{5}$.

5 Segundo Varsano (1996:5): “Assim, embora não tenha promovido uma reforma da estrutura tributária, a Constituição de 1946 modificou profundamente a discriminação de rendas entre esferas de governo, institucionalizando um sistema de transferências de impostos. Esse sistema foi, mais tarde, já no início da década de 1960, reforçado pela Emenda Constitucional número 5, que atribuiu aos municípios $10 \%$ da arrecadação do imposto de consumo e aumentou de 10 para $15 \%$ a participação dos mesmos no IR.” 


\subsection{A crise dos anos 1960}

A crise do início dos anos 1960 envolve o esgotamento da forma de Estado e Federação que vinha sustentando a transformação produtiva. Representava o encontro das pendências mais importantes não resolvidas durante a formação nacional, como, por exemplo, a reforma agrária. Ao mesmo tempo, a crise traduzia a inexistência de um padrão de financiamento adequado aos requisitos de uma nação inserida dinamicamente na onda expansiva da segunda revolução industrial nos anos dourados do capitalismo.

Desde sempre, crises são momentos históricos reveladores dos vícios da formação nacional. Quarenta anos depois, no começo do século XXI, o aprendizado dessa crise passa pelo resgate das questões que se abriam nesse momento para o desenvolvimento capitalista. Seguindo Draibe (1985), pensamos nas vias de desenvolvimento que a crise poderia produzir. Embora tanto tempo depois muitos aspectos daqueles anos possam ser resgatados e elevados à condição de conduzir o futuro, pensamos que a crise do início dos anos 1960 e seu desfecho trágico abririam a possibilidade histórica de fazer a revolução do Welfare State no Brasil, atendendo aos desafios da construção de uma democracia de massa. Mas essa tarefa moderna certamente esbarraria na magnitude de algumas pendências históricas, cuja solução, na segunda metade do século XX, requisitaria enormes mudanças nas estruturas de poder caso, por exemplo, fosse tentada uma reforma agrária num país de maioria rural, sem direitos sociais, com uma agricultura ainda precariamente industrializada e com enormes massas de população urbana à margem do processo de industrialização, desde sempre empobrecidas e também sem direitos sociais. Redistribuir o poder significava diminuir o peso das forças centrífugas que vinham marcando as relações federativas ${ }^{6}$. O aprofundamento democrático trazia em si a possibilidade de transformar essa população em consumidora de massa, dando novo destino à via capitalista. Essa questão assumia quase que simultaneamente uma dimensão regional, pois a construção do mercado interno e a integração nacional vinham, ao longo do tempo, trilhando um caminho fortemente concentrado em um Estado da Federação e na região por onde o Brasil começou, por demais populosa, sofrendo os piores males do subdesenvolvimento. A construção dos alicerces desse edifício social exigia

6 Segundo Rezende \& Afonso (2002:9): “As raízes do problema se alimentaram das enormes desigualdades regionais. Não por acaso, os momentos de virada desses ciclos estão associados a mudanças no ambiente socioeconômico que enfraqueceram as forças que sustentavam o status quo. A questão em pauta era a crescente preocupação em outras regiões - principalmente o Sul e o Nordeste - com o domínio cada vez maior do Sudeste - São Paulo e Minas Gerais - nos assuntos econômicos e políticos, após a abolição da escravatura e o primeiro movimento de industrialização. A região mais próspera exigia um papel menor para o governo central e mais autonomia estadual. As mais atrasadas viam em um governo federal forte a única maneira de fazer seus interesses prevalecerem no planejamento de políticas de desenvolvimento." 
enfrentar, previamente, entre outras questões igualmente relevantes, a reforma agrária e a questão regional. Essa utopia foi enterrada com o golpe, que deu novo sentido às reformas necessárias.

\section{O regime autoritário}

Sob o regime militar iniciou-se uma nova etapa do federalismo brasileiro. Em primeiro lugar, as relações federativas caminharam em direção a um padrão de relacionamento fortemente centralizado, expresso política e economicamente na concentração do poder decisório no governo federal. Observe-se, contudo, que as relações federativas apoiadas em relativa descentralização e autonomia dos governos estaduais foram mantidas até pouco depois de 1967. Nas suas intenções, a reforma tributária visava manter esse perfil, mas, com a edição do Ato Institucional n. ${ }^{\circ}$ 5, em 1968, o regime acelerou o percurso centralizador?

Diferentemente da era de formação do Estado e do federalismo, agora existiam bases materiais capazes de gerar recursos fiscais para bancar os "novos" arranjos de poder. As ações do regime militar, antes mesmo da reforma tributária, permitiram melhorar o desempenho dos tributos disponíveis e, a partir da reforma, realizou-se a adaptação do sistema às condições vigentes de acumulação de capital. O desempenho da carga tributária em relação ao PIB brasileiro ilustra, sob essa ótica, o sucesso das mudanças. A tabela 1.1 mostra que, em 1965, a receita tributária total disponível representava $19 \%$ do PIB e, em 1972, 26\%. Também pode-se observar como a União aumentou sua participação na receita tributária disponível total em detrimento dos Estados e dos municípios, 54,8\% em 1965 e 69,1\% em 1977. Os Estados, que abocanhavam 35,1\% em 1964, passaram para 22,3\% em 1977 .

Ao mesmo tempo, as relações entre as esferas de governo ganham complexidade pela multiplicação de novos canais de relacionamento financeiro proporcionados principalmente pela administração descentralizada (empresas estatais, fundações e autarquias) e por uma rede de mecanismos de crédito (que remetem à reforma financeira).

Durante o regime militar, as relações intergovernamentais e o federalismo tributário apresentaram vários ciclos com características bastante específicas. O primeiro, relativamente curto, entre 1964 e 1966; o segundo, entre

7 "A crise política de 1968, culminando com a promulgação do AI-5, marcou um momento de forte centralização política e o abandono da retórica liberalizante adotada até então. A consolidação do regime autoritário tornou possível aos mentores oficiais livrarem-se das amarras institucionais e conduzirem suas ações com graus de liberdade desconhecidos” (Lopreato 2003:53). 
1967 e 1976; e o terceiro, entre 1977 e 1984. Optamos por manter o ano de 1984 como sendo aquele que marca o fim da ditadura e o começo da transição democrática.

O primeiro ciclo do federalismo autoritário, entre 1964 e 1966, com freqüência é visto como um interregno benigno, dois anos de sobrevivência do padrão descentralizado anterior aliado a uma reforma tributária inicialmente concebida para garantir as autonomias anteriores, adaptar o sistema às condições de acumulação capitalista vigentes, melhorando seu desempenho, e assegurar ao governo federal a maior parcela da arrecadação nacional (Oliveira 1995:17 et seq.). Por outro lado, sua concepção original comportava um sistema de transferências inédito, precariamente comparável ao de 1946, orientado para equalizar o poder fiscal dos governos estaduais e municipais.

A partir de 1968 observa-se uma inflexão, pela qual o governo federal passa a usar e alterar o sistema vigente, sem nenhum tipo de controle federativo, e a exercer seu poder discricionário sobre os fundos públicos transferíveis, ora retendo recursos, ora liberando fora das estruturas orçamentárias. O principal aspecto se refere a seu caráter assimétrico, altamente concentrador de recursos na esfera federal e gerador de um estrangulamento fiscal dos Estados e municípios inédito na história do país. Durante esses anos, a Federação não foi reduzida a mera retórica porque o milagre e suas fantásticas taxas de crescimento atenuaram um pouco seu caráter concentrador. Por outro lado, o Fundo de Participação dos Estados garantiu recursos orçamentários às unidades mais frágeis e distantes da dinâmica do milagre. Esse sistema de transferências serviu para costurar o pacto de dominação com a anuência das oligarquias das regiões mais pobres (Lopreato 2002).

Em 1968, com a edição do AI-5, o regime enterrou os resquícios autonomistas do período anterior. O Fundo de Participação dos Estados e Municípios (FPEM) teve seus recursos diminuídos e a liberação de recursos condicionada a planos de aplicação que demonstrassem a adesão das unidades às diretrizes ou programas federais. A perda de autonomia traduziu-se em um maior controle federal sobre o gasto público.

A situação anterior, contudo, acabou gerando não apenas o estrangulamento fiscal dos governos subnacionais, mas provocou também uma alteração nas relações inter e intragovernamentais, mediante o processo de busca de financiamento e endividamento. Esse aspecto completa a visão de um padrão de financiamento estadual que resulta da combinação entre estrangulamento fiscal e liquidez creditícia frouxa, em parte explicada pela situação internacional. Vejamos como Lopreato (2002:61) avalia essa química federativa:

Assim, a dependência de recursos com origem em órgãos oficiais ou em operações de créditos controladas e aprovadas em instâncias federais 
abriu espaços para intervenções na programação de gastos estaduais e para a sua subordinação a decisões emanadas do poder central. A centralização tributária e o controle dos fluxos financeiros garantiram à União formas concretas de transferir ao plano econômico a lógica da concentração do poder já plenamente delineada em termos políticos. Desse modo, estreitando a capacidade de os Estados controlarem os recursos de investimentos, a União acabou por limitar a liberdade de as autoridades estaduais fixarem as prioridades dos gastos e buscarem soluções por vezes discordantes das determinações federais.

\section{TABELA 1. PARTICIPAÇÃO DE CADA NÍVEL DE GOVERNO NAS RECEITAS TRIBUTÁRIAS DISPONÍVEIS - 1960-2000}

\begin{tabular}{|c|c|c|c|c|c|c|}
\hline \multirow[b]{2}{*}{ ANO } & \multirow{2}{*}{$\begin{array}{c}\text { Receita } \\
\text { tributária } \\
\text { total } \\
(\% \text { do PIB })\end{array}$} & \multicolumn{3}{|c|}{ Federal } & \multirow[b]{2}{*}{ Estadual } & \multirow[b]{2}{*}{ Local } \\
\hline & & Total & Imposto $^{(1)}$ & $\begin{array}{l}\text { Contrib. } \\
\text { Sociais }^{(2)}\end{array}$ & & \\
\hline 1960 & 17,4 & 59,5 & 59,5 & - & 34,1 & 6,4 \\
\hline 1965 & 19,0 & 54,8 & 54,8 & - & 35,1 & 10,1 \\
\hline 1970 & 26,0 & 60,8 & 60,8 & - & 29,2 & 10,0 \\
\hline 1971 & 25,3 & 62,8 & 62,1 & 0,8 & 27,3 & 9,9 \\
\hline 1972 & 26,0 & 63,8 & 61,8 & 2,1 & 26,9 & 9,2 \\
\hline 1973 & 25,0 & 64,5 & 61,4 & 3,1 & 26,3 & 9,2 \\
\hline 1974 & 25,1 & 66,4 & 62,6 & 3,8 & 25,2 & 8,4 \\
\hline 1975 & 25,2 & 68,0 & 63,7 & 4,3 & 23,3 & 8,7 \\
\hline 1976 & 25,1 & 68,1 & 63,5 & 4,7 & 23,1 & 8,8 \\
\hline 1977 & 25,6 & 69,1 & 64,2 & 4,9 & 22,3 & 8,6 \\
\hline 1978 & 25,7 & 68,1 & 63,1 & 5,0 & 23,3 & 8,6 \\
\hline 1979 & 24,7 & 68,0 & 63,3 & 4,7 & 22,7 & 9,3 \\
\hline 1980 & 24,5 & 68,2 & 64,0 & 4,2 & 23,3 & 8,6 \\
\hline 1981 & 25,3 & 68,4 & 64,3 & 4,2 & 22,3 & 9,3 \\
\hline 1982 & 26,3 & 69,0 & 64,1 & 4,8 & 22,1 & 8,9 \\
\hline 1983 & 27,0 & 69,8 & 64,0 & 5,8 & 21,3 & 8,9 \\
\hline 1984 & 24,3 & 65,8 & 60,1 & 5,7 & 24,1 & 10,1 \\
\hline 1985 & 24,1 & 62,7 & 56,7 & 5,9 & 26,2 & 11,1 \\
\hline 1986 & 26,2 & 60,9 & 54,2 & 6,7 & 27,0 & 12,1 \\
\hline 1987 & 23,8 & 64,1 & 58,0 & 6,2 & 23,3 & 12,6 \\
\hline 1988 & 22,4 & 60,1 & 55,2 & 4,9 & 26,6 & 13,3 \\
\hline 1989 & 24,1 & 61,1 & 52,9 & 8,1 & 25,0 & 13,9 \\
\hline 1990 & 28,8 & 58,9 & 47,7 & 11,2 & 27,6 & 13,5 \\
\hline 1991 & 25,2 & 54,6 & 43,2 & 11,4 & 29,6 & 15,7 \\
\hline 1992 & 25,0 & 56,9 & 45,6 & 11,3 & 28,1 & 14,9 \\
\hline 1993 & 25,8 & 57,8 & 44,6 & 13,2 & 26,4 & 15,8 \\
\hline 1994 & 29,8 & 59,3 & 40,3 & 19,0 & 25,1 & 15,6 \\
\hline 1995 & 29,4 & 56,2 & 41,7 & 14,5 & 27,2 & 16,6 \\
\hline 1996 & 29,1 & 56,0 & 42,6 & 13,5 & 27,6 & 16,3 \\
\hline 1997 & 29,6 & 56,2 & 40,9 & 15,4 & 27,7 & 16,1 \\
\hline 1998 & 29,6 & 56,2 & 41,6 & 14,6 & 26,6 & 17,2 \\
\hline 1999 & 31,7 & 57,0 & 38,9 & 18,1 & 26,0 & 17,0 \\
\hline 2000 & 32,7 & 56,7 & 36,7 & 20,1 & 26,4 & 16,9 \\
\hline
\end{tabular}

FONTE: Varsano et al. (1998) e Araújo (2001). (1) Impostos, contribuições para a previdência social e seguro desemprego. (2) Impostos sobre transações, sobre transações financeiras e sobre lucro líquido. 
A centralização fiscal, financeira e política aumentou as distâncias em relação às demandas sociais, já que favoreceu a orientação economicista do governo federal, contudo, os mecanismos de cooptação garantiram vantagens às elites locais, para as quais, via de regra, a sobrevivência econômica e política comandava suas escolhas e justificava sua submissão ao poder central.

O último ciclo federalista do regime militar, entre 1976 e 1984, embora aponte para uma certa reversão das tendências centralizadoras anteriores e coincida com alguma abertura política, não deve levar a acreditar num conjunto de fatores que articuladamente agem para mudar o pêndulo federativo. Antes de mais nada, o que se observa é o progredir de uma crise política e de financiamento que, desde o fim do milagre, vinha mostrando contradições não triviais. A estratégia do II PND, naquilo que os historiadores caracterizam como sendo uma "fuga para a frente", intentou adiar uma reformulação profunda no papel político e econômico do Estado que, para muitos, ficou patente com a desaceleração do crescimento, a inflação e os impactos do choque do petróleo de 1973 e, depois, de 1979. Sem contar com a mesma disposição e composição do capital privado nacional e internacional para produzir crescimento econômico, o Estado chamou a si a responsabilidade pelo crescimento econômico e, portanto, para continuar validando o pacto de dominação. A ascensão de Geisel, a desconcentração espacial das atividades produtivas e a abertura política constituem fenômenos correlatos à deterioração das condições de financiamento da economia brasileira a partir da segunda metade dos anos 1970.

A partir de 1976, a estratégia originalmente planejada foi destruída e substituída por uma política de acerto ad hoc com os interesses setoriais e regionais envolvidos com a via voluntarista de acumulação escolhida pelo regime na sua longa agonia. Em última instância, a oferta de crédito externo permitiu a reprodução das relações inter e intragovernamentais não fiscais incentivadas no âmbito do pacto de dominação e de concentração do poder no governo federal desde 1964. As operações de crédito foram transformadas em elo crucial do federalismo "fiscal" brasileiro, pelas quais as esferas de governo, de modo cada vez mais precário, tentavam ajustar os interesses privados inteiramente descolados das condições fiscais específicas. Durante os anos 1970, particularmente a partir da segunda metade, acelera-se um fenômeno de descentralização dos aparelhos públicos brasileiros, pondo em ação uma tendência que alguns autores denominam de "centrifugação do poder estatal", de alguma maneira onipresente em cada parte do país e em todas as esferas, para isso mimetizando-se com os poderes locais. 
O último dos governos militares foi, sob uma ótica estritamente econômica, o pior de todos. Esgotaram-se quase totalmente os impulsos dinâmicos dos investimentos comandados pelo II PND e o endividamento externo imprudente tornara-se crítico, escancarando a vulnerabilidade do País diante da elevação acentuada da taxa de juros internacional, rebatendo na crise do balanço de pagamentos. A política econômica militar respondeu com o famoso "exportar é o que importa", promovendo duas grandes desvalorizações cambiais e intermináveis "minis". O drive exportador buscava gerar divisas e "proteger" as relações com o sistema financeiro internacional. A gestão do balanço de pagamentos, para atender ao descomunal passivo externo, subordinou todos os campos da política econômica: internamente gerava-se recessão, inflação e ciranda financeira.

A política fiscal passava a buscar austeridade como meta permanente e a política monetária tornava-se totalmente restritiva, encarecendo o crédito doméstico com taxas de juros elevadíssimas. Iniciara-se um longo ciclo em que difícil era saber quem corria mais e quem determinava quem, se o ritmo da desvalorização cambial, da inflação ou da taxa de juros. Esse foi o cenário econômico durante o qual ocorreu a transição regulada para a democracia e, também, o que empobreceu e retardou seus resultados. $\mathrm{O}$ ajuste do governo militar serviu para implodir as condições de financiamento do setor público; a crise do financiamento da economia tinha como epicentro o Estado, sua crise revelava o esgotamento da alternativa autoritária. Chegava ao fim a economia política da centralização financeira estatal, que, em sua longa caminhada em estado crítico, socializou prejuízos no plano doméstico sem, contudo, ter abandonado o mandato de organizar e comandar a produção de divisas para os credores externos. A crise do Estado era simultaneamente a crise da Federação, com os governos estaduais vendo as receitas próprias debilitadas pela combinação de recessão e inflação e suas instituições de financiamento e empresas bloqueadas por dívidas.

Observe-se que a desordem fiscal e financeira, permeando as relações federativas, convive com um outro processo já citado acima: o de descentralização decorrente da desconcentração econômica regional impulsionada pelo II PND e pela abertura política ${ }^{8}$. Talvez, mais correto do que identificar um processo de descentralização seja apontar a fragmentação do sistema federativo armado pelo regime militar e cada vez mais questionado pela oposição ascendente.

8 Segundo Rezende \& Afonso (2002): "Emendas constitucionais promulgadas em 1975 e 1980 levaram a um progressivo aumento da participação dos Estados e dos municípios na arrecadação federal do IPI e do IR. Em conseqüência, os Estados e os municípios recuperaram as perdas causadas em 1968 (a porcentagem desses dois impostos que compõem o FPE e o FPM atingiu 10,5\% em 1983).” 
O colapso do financiamento externo entre 1980 e 1983 iniciou o xequemate desse sistema de relações federativas coeso no crédito frouxo. Progressivamente, as unidades federativas viram cessar a correia de transmissão do crédito farto e foram cada vez mais invadidas pelas condições adversas da economia brasileira. Simultaneamente, os governos estaduais respondiam pela democratização e enfrentavam, em plena crise, as demandas sociais por um utópico welfare state. No campo das relações intragovernamentais, o ativismo fiscal decorrente da democratização e dos compromissos de poder levou, durante os anos 1980, à implosão do circuito que envolvia os tesouros estaduais e os bancos estaduais, usados como bancos centrais geradores de poder de gasto pela via do endividamento, o qual podia ser camuflado pelos lucros financeiros gerados pela ciranda e o floating.

\section{O caminho democrático}

Em termos federativos, o avanço da democracia efetivamente traduziuse num aumento da participação dos governos subnacionais na receita tributária total. Contudo, a profundidade da crise e a capacidade política de o governo federal incorporar dívidas dos governos estaduais e municipais ao seu descomunal estoque de dívida condicionaram a autonomia que supostamente seria conquistada pelos governos subnacionais num processo de descentralização fiscal.

Convém repassar alguns dos eventos mais importantes que marcaram a crise das relações intergovernamentais, das finanças públicas estaduais e o processo de descentralização na década de 1980 e, mais especificamente, entre 1984 e 1989.

1. As relações fiscais e financeiras entre a esfera federal e os governos estaduais nos anos 1970 envolviam transferências negociadas ou não, concessão de financiamentos, autorizações para operações de crédito e, certamente, discussão e execução de normas referentes ao controle do endividamento. Mas esse sistema de "concessões" estava condicionado à execução de determinados programas e projetos de interesse estratégico do regime autoritário. Dessa maneira, exercia-se o controle sobre os gastos dos níveis inferiores de governo e, ao mesmo tempo, por envolver a realização de investimentos, via de regra, obtinha-se o apoio dos blocos de poder regional. Nos anos 1980, sob o governo Sarney, as relações intergovernamentais envolviam os ingredientes anteriores, só que cada vez mais referidos a 
uma lógica perversa de endividamento crescente, queda dos investimentos públicos e pagamento de juros, numa fuga para a frente, em que os governos subnacionais procuravam transferir para o governo federal o ônus do endividamento, e este usava seu poder de incorporar dívidas a seu gigantesco estoque, como arma para acomodar interesses políticos. Esse jogo de "empurra-empurra" (Lopreato 1992), somado à descentralização da receita tributária e à maior autonomia em matéria tributária (antes mesmo da reforma constitucional de 1988), permitiu que as finanças públicas estaduais navegassem pela crise de financiamento sem chegar ao colapso, pelo menos até o fim da transição democrática.

2. O modo como cada um dos governos estaduais atravessou esse período crítico de esgotamento do padrão de financiamento esteve vinculado não apenas à deterioração das condições gerais de funcionamento das relações intergovernamentais mas, também, à qualidade da gestão fiscal dos Estados e de suas relações intragovernamentais com suas empresas públicas e instituições financeiras.

3. A recessão, combinada com taxas elevadas de inflação crônica durante quase toda a década, gerou efeitos negativos nas bases tributárias de todas as esferas de governo no país, com poucas e curtas exceções, por exemplo, em algumas regiões ligadas ao drive exportador e seus efeitos dinâmicos limitados em investimentos imobiliários.

4. A força dos governadores eleitos permitiu certa descentralização dos recursos tributários quase totalmente anulada pela deterioração das bases tributárias em decorrência da crise da economia, instabilidade e inflação crônica. Ao longo do tempo, a descentralização fiscal pareceu focar mais os municípios brasileiros do que os governos estaduais.

5. As finanças públicas foram sendo debilitadas pelo peso dos juros no conjunto dos gastos e pela imperiosa necessidade de cortar ou limitar gastos correntes. Em boa parte das unidades estaduais, a interrupção do crédito público tendeu a exacerbar a utilização das instituições financeiras públicas estaduais e das empresas públicas estaduais enquanto supridores de recursos para os respectivos governos, resolvendo, assim, problemas de curto prazo, porém gerando metástase no conjunto do setor público.

6. Em 1988, a nova Constituição, chamada de cidadã, buscou, nas condições críticas vigentes, fazer um acerto de contas com o passado, universalizando tardiamente direitos civis e sociais. No plano das relações federativas, tratou-se de reforçar o poder político e financeiro dos Estados e municípios, acelerando o processo de 
descentralização fiscal iniciado junto com a democratização do País. O sistema tributário contido na Constituição refletiu tal objetivo (aumentar a autonomia política e o poder financeiro dos governos subnacionais), pois a partir dele realizou-se uma expressiva redistribuição do bolo tributário em direção às esferas inferiores de governo e, também, uma "ampliação e fortalecimento das competências tributárias próprias” (Afonso 1994:21). Os Estados passaram a ser peças-chave na formulação da política tributária federal ao controlar o principal imposto indireto sobre o valor adicionado do país: o Imposto sobre Circulação de Mercadorias e Serviços (ICMS), tendo tido sua base ampliada pela incorporação de tributos que antes eram competência da União.

7. Em 1989, o País vivia uma crise monetária aguda, com riscos elevados de hiperinflação e desvalorização dramática dos patrimônios acumulados e perda da legitimidade da riqueza (Belluzzo \& Almeida 2002:279), cuja origem estava na crise da dívida em 1982 e nos ajustes realizados para enfrentá-la. O campo fiscal do Estado, incluindo união, Estados e municípios, era um dos pontos de chegada dessa crise, não havendo possibilidade de resolução de seus problemas específicos sem, antes, resolver os problemas mais gerais do padrão monetário e de financiamento da economia.

\subsection{Reversão do Estado brasileiro: 1990-1994}

Com as eleições presidenciais em 1989 e a posse do novo presidente em 1990 chegava ao fim a longa transição democrática. Observe-se que, sob uma situação econômica crítica, os últimos anos da década de 1980 foram politicamente cruciais para o pleno estabelecimento da democracia: um processo constituinte do qual resultou uma Constituição que consagrava, no espírito da lei a reger o País, os direitos sociais na vida dos cidadãos e, pouco depois, uma escolha presidencial que, pela primeira vez, contava com o voto universal.

Entretanto, ficava para os futuros mandatos presidenciais o enfrentamento dos principais problemas econômicos, entre eles a crise fiscal e financeira do Estado, a inflação crônica elevada e o modo de inserção do País na economia mundial.

A crise fiscal e financeira do Estado, em sua dimensão federativa, incluía a crise das finanças públicas estaduais e, dentro destas, a questão do endividamento e suas formas de controle. As falhas do processo constituinte vinculadas ao federalismo fiscal brasileiro, acima citadas (Lopreato 2002), deixaram a porteira aberta para a guerra fiscal entre Estados e municípios. A meta de aumentar a participação 
nas receitas tributárias totais, que gerou consenso entre os governos subnacionais, era muito pouco para um País que precisava redesenhar as relações federativas. Portanto, ficavam em aberto para os novos governadores não apenas as vias de saneamento das finanças públicas dos seus Estados mas, também, os mecanismos de articulação e os efeitos nacionais das políticas estaduais de desenvolvimento que fossem implementadas no futuro. Assim, o período 1990-1994 foi marcado por miniciclos estabelecidos pela política econômica e negociações duras do governo Collor com os governos estaduais até o impeachment em 1992 e, depois, pelo interregno de Itamar Franco e a gestão dos seus três ministros da Fazenda, Fernando Henrique Cardoso, Rubens Ricupero e Ciro Gomes, que tiveram papel importante na preparação do Plano Real.

\subsection{O Estado brasileiro na fase de estabilização econômica: 1995-1998}

A partir de 1994 há um deslocamento político importante no sentido de desobstruir o caminho para a resolução (por algum tempo) de alguns problemas graves da crise do Estado, entre eles a questão do desequilíbrio patrimonial mediante a venda de ativos. Observe-se que a execução dessa alternativa não visou apenas anular passivos mediante a venda de ativos públicos mas, principalmente, oferecer uma porta de entrada ao capital internacional e assegurar a ancora-

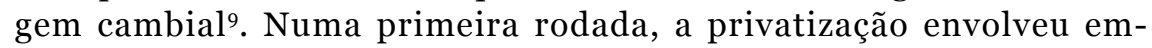
presas públicas da esfera federal, depois avançou para as empresas públicas estaduais e instituições financeiras públicas estaduais, sendo parte da estratégia de saneamento das finanças públicas.

Numa linha de análise complementar e, talvez, mais vinculada às políticas estaduais de desenvolvimento, não se deve perder de vista que a privatização e a cessão (por meio de várias modalidades contratuais) ao setor privado do direito de explorar a oferta de bens semipúblicos significaram também a realização de novos arranjos políticos com os grupos

9 Belluzzo \& Almeida (2002:366-7) mostram aspectos importantes da articulação interna-externa que sustentou o Plano Real: "Os países da periferia, o Brasil inclusive, até então submetidos às condições de ajustamento impostas pela crise da dívida, foram literalmente capturados pelo processo de globalização, executando seus programas de estabilização de acordo com as normas dos mercados financeiros liberalizados. A regra básica das estabilizações com abertura financeira é a da criação de uma oferta de ativos atraentes que possam ser encampados pelo movimento geral de globalização. Nesse rol estão incluídos títulos da dívida pública, em geral curtos e de elevada liquidez; ações de empresas em processo de privatização; bônus e papéis comerciais de empresas e bancos de boa reputação; e posteriormente, ações depreciadas de empresas privadas, especialmente daquelas mais afetadas pela abertura econômica, valorização cambial e taxas de juros altas.” 
privados destinatários das áreas de interesse. Esse processo político estaria a confirmar que, assim como na esfera superior de governo, nas esferas inferiores, em particular nos Estados, novas composições de poder poderiam estar justapondo-se àquelas que sobreviveram aos tempos. Essa questão assume relevância quando o foco são as políticas de desenvolvimento, pois condiciona ou limita seu alcance e, mais, torna complicado alterar seu curso.

Assumindo a hipótese de que a guerra fiscal seja a contracara de políticas estaduais de desenvolvimento "autônomas e agressivas" num cenário de fragmentação das interconexões regionais e federativas, não adiantaria focar exclusivamente as reformas possíveis do campo tributário para coibi-la sem, antes, realizar uma análise profunda das convergências e divergências entre as políticas estaduais de desenvolvimento que estão sendo executadas.

A guerra fiscal ${ }^{10}$ entre os governos estaduais, na segunda metade da década de 1990, esteve correlacionada à onda de investimentos estrangeiros da indústria automobilística em fase de reestruturação mundial que ocorreu no período, envolvendo relocalização de atividades. Sob uma postura tolerante do governo federal, o embate entre os governos subnacionais e a negociação com as grandes empresas demonstraram uma faceta perversa da descentralização fiscal ocorrida no Brasil. A entrada dos investimentos não obedeceu a nenhuma orientação política nacional, nem de política industrial, nem de política regional. Diferentemente de outras épocas, as negociações não envolveram o governo federal (este apenas garantia os parâmetros da abertura da economia). $\mathrm{O}$ comportamento dos governos subnacionais que entraram na disputa resgatou também uma informação genética do federalismo brasileiro: as autonomias relativas das unidades federativas encobrem a existência de grupos de poder heterogêneos que dificultam a formação de identidades horizontais entre as regiões e, também, no seu interior. A Federação da República Velha dava sustentação (precária) aos arquipélagos regionais e suas respectivas oligarquias. Talvez por isso a enorme heterogeneidade regional e as distâncias sociais do País estejam na origem dos gravíssimos problemas de coordenação que afligem o federalismo brasileiro.

10 Segundo Prado e Cavalcanti (2000:11) a guerra fiscal: “(..) é um caso de uma classe geral de fenômenos que emergem quando iniciativas políticas de governos subnacionais adquirem conotações negativas e geram efeitos econômicos perversos em decorrência do caráter insuficiente ou conjunturalmente inoperante do quadro político institucional que regula os conflitos federativos, o qual se revela incapaz de garantir um equilíbrio mínimo entre interesses locais para evitar efeitos macroeconômicos e sociais perversos. No caso em questão, essas iniciativas são o uso de benefícios e incentivos fiscais com a finalidade de induzir a alocação de investimentos nos territórios locais". 
Não é, portanto, inteiramente apropriado indicar, a título de justificativa, que o fenômeno decorre apenas do vazio deixado pela crise das políticas nacionais de desenvolvimento regional, já que a modalidade de política subnacional, de perfil individualista e agressivo, que ocupou esse espaço apresenta elementos de continuidade histórica razoáveis que não foram eliminados pelo Estado, apesar da retórica oficial que, a partir da estabilização da economia, aponta a existência de esforços relativamente bem-sucedidos de ordenar e disciplinar a miríade de relações intergovernamentais do País. Ao mesmo tempo, há aspectos específicos vinculados ao quadro político institucional inoperante diretamente responsável, no campo estritamente fiscal, pela guerra fiscal. Esse quadro decorre das especificidades que regem o sistema de tributação do ICMS - competência estadual com princípio predominantemente de origem - e da falta de efetividade do Conselho Nacional de Política Fazendária (Confaz) para realizar o enforcement dos dispositivos existentes e coibir a utilização predatória de instrumentos fiscais (Prado \& Cavalcanti 2000:14 et seq.).

Rodrigues (1995:443) faz uma interessante tipologia ou caricatura do comportamento que marca a ação política dos governadores no que denomina de federalismo estadualista:

A ação dos atores que se encontram no interior do que estamos chamando de "política dos governadores num federalismo estadualista" se caracteriza, em geral, por:

- um comportamento de negociador maximizador. Esse ator político não tem agenda de negociação, pois busca o atendimento total de suas demandas, e somente em função de obter uma parte delas, faz alianças. Nunca está disposto a ceder nada, uma vez que entra na negociação já com perdas e precisa recuperá-las;

- uma ação individual. Não existe coletivo, nem no plano institucional nem na representação ideológica. No plano institucional, mobiliza seus recursos de poder para inutilizar os espaços institucionais coletivos. No âmbito ideológico, utiliza-os para maximizar suas demandas individuais. O sentimento para uma representação coletiva inexiste; portanto, não entram em seus cálculos demandas como solidariedade social ou nacional;

- uma agenda oculta. Raramente torna pública sua agenda política, e sua ação política é regida por pleitos não explicitados. Nessas condições, resulta difícil estabelecer uma agenda de negociação, prioridades e alianças estáveis. Pensamos que essa é uma das características do atual conflito federativo brasileiro. 
Neste começo de século, o panorama das finanças públicas estaduais encontra-se bem próximo do ideal apregoado por vários autores que, durante a última década, representaram o mainstream da boa gestão fiscal e da reforma do Estado. Para esses autores, a governabilidade macroeconômica exigia que as esferas de governo estivessem desprovidas de instituições financeiras para evitar trajetórias de gastos acima da realidade fiscal, afastando o sobreendividamento e, completando o ideal-tipo, a privatização de empresas públicas para alcançar maiores níveis de eficiência e eficácia econômica. $\mathrm{O}$ arranjo defendido, fazendo lembrar o supply side economics, afirma que essa saída permitirá dinamizar o setor privado e a realidade do mercado.

\subsection{Restrição nas Metas Fiscais Estaduais: uma conseqüência da Lei de Responsabilidade Fiscal}

A história recente mostra que, sob a estabilização do real, o governo federal, demonstrando inédita força programática em vinte anos, numa negociação abrangente das dívidas dos governos estaduais, impôs a execução de programas de privatização de bancos e empresas públicas (Lopreano 2000). A assinatura dos acordos, a maior parte deles em 1998, talvez tenha servido para evitar ou adiar uma crise final de conseqüências imprevisíveis, dada a magnitude do endividamento.

Em 2003, começou um novo ciclo de governos estaduais, e os recémeleitos encontraram, sob a vigência da Lei de Responsabilidade Fiscal (LRF), uma situação com pouca margem de manobra: parcela expressiva das receitas próprias comprometidas com o pagamento de dívidas junto ao governo federal. Sem o poder de comando sobre os investimentos que o sistema de empresas públicas federais "estadualizadas" podia lhes dar na etapa anterior e sem a possibilidade de produzir dívidas usando instituições públicas estaduais, os governos estaduais tiveram que se submeter às metas globais de superávits primários e abdicar de qualquer folga orçamentária mais duradoura.

Segundo Giubert (2005), com o intuito de controlar o gasto público em todas as esferas de governo, a LRF se concentrou em dois itens de finanças públicas: o endividamento e a despesa com pessoal. Na aplicação da LRF, para adequar os contratos das dívidas estaduais à LRF, os Estados tiveram que reduzir acentuadamente a parcela de suas receitas destinadas aos gastos com folha de pagamentos, de modo a garantir a si próprios as condições necessárias para absorver choques fiscais e implementar as demais políticas (OCDE 2001). 


\section{Conclusão}

O objetivo do artigo foi discutir as relações federativas no País sem perder de vista a questão da formação do Estado capitalista no País até o início dos anos 1960 e seus desdobramentos na fase pós-autoritarismo.

No período 1889-1930, grupos de interesses dominaram e assumiram o controle dos assuntos políticos no Brasil. Com a Constituição de 1891, as províncias transformaram-se em Estados, o que permitiu a criação de suas próprias constituições e a possibilidade de eleger seus próprios governadores. Como havia autonomia para legislar sobre tributos, os Estados puderam introduzir inúmeros outros impostos sobre operações diversas de âmbito estadual, porém sem resultados consistentes em termos de arrecadação. Assim, um conjunto relevante de Estados com menor dinamismo econômico se tornou dependente da capacidade política de obter parcelas de recursos do orçamento da União.

A crise dos complexos, em especial do cafeeiro, e a Revolução de 1930 abriram um novo período marcado pelo avanço na construção de aparelhos centralizadores do Estado no seio da dinâmica de industrialização restringida. Em função disso, observa-se uma centralização do poder político, haja vista que os governos estaduais e locais, assim como seus poderes (Executivo e Legislativo) foram abolidos.

Com o fim do Estado Novo, em 1946, o País iniciava um ciclo democrático até o golpe militar de 1964, período de quase vinte anos em que houve muitas mudanças na base econômica, no Estado e na Federação. Do ponto de vista fiscal, a Constituição de 1947 possibilitou uma maior descentralização fiscal, sobretudo com o sistema de compartilhamento de tributos.

Sob o regime militar iniciou-se uma nova etapa do federalismo brasileiro. No período 1964-1985, o poder político foi centralizado, assim como a administração tributária. Acompanhado ao período centralizador, a busca por maior autonomia financeira, tendo como respaldo a oposição dos Estados e municípios, permitiu uma nova onda de descentralização política. O ativismo fiscal decorrente da busca pela democratização e dos compromissos de poder levou, durante os anos 1980, à implosão do circuito que envolvia os tesouros estaduais e os bancos estaduais, usados como bancos centrais geradores de poder de gasto pela via do endividamento, o qual podia ser camuflado pelos lucros financeiros gerados pela ciranda e o floating. Assim, a dependência do financiamento discricionário promoveu um comportamento fiscal irresponsável.

Em termos federativos, o avanço da democracia efetivamente traduziuse num aumento da participação dos governos subnacionais na receita 
tributária total. Com o restabelecimento da democracia em 1985, observou-se uma aceleração no processo de descentralização política, elevando a participação na arrecadação dos governos estaduais e municipais.

Ao longo de toda a década de 1990, as discussões federativas podem ser divididas em dois períodos. No primeiro, entre 1990 e 1994, observa-se miniciclos estabelecidos pela política econômica e negociações duras do governo Collor com os governos estaduais, conduzidas, posteriormente, pelo interregno de Itamar Franco e a gestão dos seus três ministros da Fazenda, Fernando Henrique Cardoso, Rubens Ricupero e Ciro Gomes, que tiveram papel importante na busca pela retomada de um federalismo estadualista, sobretudo, em função da necessidade de reversão do profundo desequilíbrio das relações intergovernamentais.

O segundo período é marcado pela guerra fiscal entre os governos estaduais, sendo esta associada à onda de investimentos estrangeiros da indústria automobilística em fase de reestruturação mundial que ocorreu no período, envolvendo relocalização de atividades. Sob uma postura tolerante do governo federal, o embate entre os governos subnacionais e a negociação com as grandes empresas demonstraram uma faceta perversa da descentralização fiscal ocorrida no Brasil.

Na fase pós 1999, com o intuito de controlar o gasto público em todas as esferas de governo, a LRF se concentrou em dois itens de finanças públicas: o endividamento e a despesa com pessoal; tudo isso, para garantir aos próprios Estados condições necessárias para absorver choques fiscais e implementar políticas condicionadas ao novo ciclo de abertura financeira e endividamento externo que se verificou na década de 1990.

As privatizações e a abertura da economia provocaram uma "financeirização" das decisões fundamentais do Estado, cujas políticas, cada vez mais, passam a orientar-se pelo temor real ou fictício da fuga de capitais de curto prazo e pelos interesses dos novos gestores das tarifas públicas que, apesar das agências de regulação, intentam proteger-se dos movimentos de desvalorização cambial. Quanto ao capital nacional, o produtivo, sem escalas compatíveis com a concorrência globalizada, foi debilitado pela abertura da economia, e o bancário nacional que sobrou da abertura financeira, como sempre, beneficia-se das altas taxas de juros. O Estado percorreu um caminho do "capitalismo associado" ao capitalismo das finanças globalizadas na periferia. Os interesses das classes subalternas, apesar de representados nos parlamentos das diversas instâncias federativas, não conseguiram ampliar satisfatoriamente e aprofundar as políticas sociais. Sob a descentralização, fragilizada financeiramente e com pouco lastro fiscal, realizou-se uma profunda transferência de atribuições: a pressão social e os gastos sociais cada vez mais passam pelas instâncias inferiores de governo. Em 
princípio, esse deslocamento funcional aproximaria a gestão das políticas públicas dos beneficiários, mas, na prática, o Estado perdeu força e abrangência para lidar com a questão social.

\section{Referências}

AFONSO, José Roberto Rodrigues (1994). Descentralização fiscal na América Latina: estudo de caso do Brasil. Santiago de Chile: Cepal (Série Política Fiscal, 61).

ARAÚJO, E. A. (2001). Carga Tributária - Evolução Histórica: Uma Tendência Crescente. Rio de Janeiro: BNDES, julho (Informe-se, 29).

BELLUZZO, Luiz G. \& ALMEIDA, Júlio G. (2002). Depois da queda: a economia brasileira da crise da dívida aos impasses do Real. Rio de Janeiro: São Paulo.

DRAIBE, Sônia (1985). Rumos e Metamorfoses: um estudo sobre a constituição do Estado e as alternativas de industrialização no Brasil, 1930-1960. Rio de Janeiro: Paz e Terra.

GIUBERTI, Ana Carolina (2005). Lei de Responsabilidade Fiscal: efeitos sobre o gasto com pessoal. In Anais do XXXIII Encontro Nacional de Economia ANPEC, 2005, Natal., vol 2.

LOPREATO, Francisco Luiz C. (1992). Crise de financiamento dos governos estaduais (1980/ 1988). Tese (Doutorado em Economia)- Instituto de Economia, Unicamp, Campinas.

LOPREATO, Francisco Luiz C. (2000). O endividamento dos governos estaduais nos anos 90. Campinas: IE/UNICAMP, Texto para Discussão 94.

LOPREATO, Francisco Luiz C. (2002). O colapso das finanças estaduais e a crise da federação. São Paulo: Ed. Unesp: Unicamp.

OCDE (2001). Estudos Econômicos da Organização para a Cooperação e o Desenvolvimento Econômico (OCDE): Brasil 2OoO - 2001. Rio de Janeiro: Editora FGV.

OLIVEIRA, Fabrício A. (1995). Autoritarismo e crise fiscal no Brasil (19641984). São Paulo: Hucitec.

PRADO, Sérgio \& CAVALCANTI, Carlos E. G. (2000). A guerra fiscal no Brasil. São Paulo: Fundap: Fapesp; Brasília: IPEA.

REZENDE, Fernando \& AFONSO, José R. (2002). A federação brasileira: fatos, desafios e perspectivas. In: Banco Federativo, BNDES: Brasília, dezembro.

RODRIGUES, Vicente (1995). Federalismo e interesses regionais. In: AFFONSO, Rui \& SILVA, Pedro (orgs) A federação em perspectiva: ensaios selecionados. São Paulo: FUNDAP.

VARSANO, Ricardo (1996). Evolução do sistema tributário brasileiro ao longo do século: anotações e reflexões para futuras reformas. IPEA: Rio de Janeiro, Texto para Discussão 405). 
VARSANO, R. \& AFONSO, J. R. \& ARAUJO, E. A. \& PESSOA, E. P. \& RAMUNDO, J. C. \& SILVA, N. L. (1998). Uma Análise da carga Tributária do Brasil. Brasília: IPEA, Texto para Discussão 583.

Recebido em: 23 jul. 2006 Aceite em: 19 set. 2006 